\title{
Bazı çevresel atıkların ve doğal liflerin kompozitlerde kullanılabilirliği
}

\section{Availability of some environmental wastes and natural fibers in composites}

Sevda BORAN TORUN

Karadeniz Teknik Üniversitesi, Of Teknoloji Fakültesi, Ağaçişleri Endüstri Mühendisliği, Trabzon

Eser Bilgisi / Article Info

Derleme makale / Review article

DOI: 10.17474/artvinofd.768285

Sorumlu yazar / Corresponding author

Sevda BORAN TORUN

e-mail: sboran@ktu.edu.tr

Geliş tarihi / Received

11.07.2020

Düzeltme tarihi / Received in revised form

16.10.2020

Kabul Tarihi / Accepted

28.12.2020

Elektronik erişim / Online available

12.05.2021

Anahtar kelimeler:

Atık yağ

Kompozit

Doğal lif

\section{Keywords:}

Waste oil

Composite

Natural fiber

\begin{abstract}
Özet
Ekonomik ve çevreye duyarlı kompozit malzemeler üretmek gelişmiş ve gelişmekte olan ülkelerin öncelikleri arasında yer almaktadır. Çevre kirliliğini minimize edecek çalışmalar yapılarak doğal kaynakların daha etkin kullanımını sağlamak mümkündür. Atıkların geri dönüşümü ile ekonomik kazancın yanı sıra sürdürülebilir bir kalkınma hedeflenmektedir. Atık motor yağı, atık bitkisel yağ ve atık gazete kâğıdı lifleri de bu kapsama girmektedir. Bu derlemede atıkların kompozitlerde kullanılması ile hem ülkemize katma değer sağlanacak hem de çevresel açıdan kaliteli ürünlerle iç ve dış piyasada rekabet gücümüzü arttıracak tamamen atıktan üretilmiş bir kompozit üretimi gibi çevresel bir yaklaşım sunulmuştur. Bu çalışma ile atıkların nasıl değerlendirilmesi hususu tartışılarak mevcut problemlerin çözümünü hedefleyen çevre dostu bir ürün kazandırılması zorunluluğu gelecekteki çevreye duyarlı araştırma çalışmalarına ilgi duyanlara ışık tutacaktır.
\end{abstract}

\begin{abstract}
It is among the priorities of developed and developing countries to produce economical and environmentally friendly composite materials. It is possible that more efficient use of natural resources is to be ensured by carrying out studies to minimize environmental pollution. A sustainable development is aimed as well as economic gain with the recycling of wastes. Waste motor oil, vegetable oil and newsprint fibers are also included in this scope. In this review, an ecological approach that will provide value to our country and increase our competitiveness in the domestic and foreign markets with environmentally quality products produced by using wastes in composites is presented. With this study, the obligation to acquire an environmentally friendly product that targets the solution of the problems related to wastes assessment will shed light on those interested in future environmentally sensitive research studies.
\end{abstract}

\section{GíRiş}

Son 60 yılda plastiklerin üretimi artmış ve 1950 yılında 1.5 milyon ton olan üretim 2016 yılında 335 milyon tona yükselmiştir. Kağıt ve karton 20. yüzyılda elektrik yalıtımında kullanılmak amacıyla melamin formaldehit ve fenol formaldehit esaslı kompozitlerde değerlendirilmiştir. Arabanın koltuk aksamı ve iç kısımları için sonraki yıllarda odun unu ve hindistan cevizi lifleri polipropilene (PP) katılarak kompozit üretimi gerçekleştirilmiştir (Mohanty ve ark. 2005). Endüstriyel kaplamada, 90'lı yıllarda çit duvarı ve yük platformlarında kullanılmak üzere doğal lifler ile polietilen (PE) kompozitleri üretilmiştir. Son yıllarda da kapı ve pencere uygulamalarında çokça tercih edilen polivinil klorür (PVC) kompozitlerinde odun ununun kullanılmasının uygun olduğuna dair birçok araştırma mevcuttur (Clemons 2002).
Dünyada artan sanayileşme ile orantılı olarak insanların yaşam kalitesi artmasına rağmen sanayileşme çevre sorunlarını da beraberinde getirmiştir. Atıkları geri dönüştürecek tesis eksikliği nedeniyle birçok sanayi üretimi sonucunda oluşan atıklar içme suyuna ve tarım alanlarına deşarj edilmektedir. Bu sebepten dolayı, yağ üretim tesisleri, atık yağ üreticileri ve taşıyıcıları, geri kazanım ve atıkları uzaklaştırma yetkililerin yönetmeliklere uygun hareket etmeleri gerekmektedir. Bu yağların geri kazanımı ile insan ve çevre sağlığı korunarak ekonomik değeri olan ürünler elde edilerek ülkemiz ekonomisine katkı sağlanmalı, bu söz konusu çevresel sorun bir avantaja dönüştürülmelidir (URL-1). Ülkemizde atık kullanımı kompozitlerde değerlendirilerek, hem ülkemize katma değer sağlayacak yeni bir ürün meydana getirmek hem de çevresel açıdan kaliteli ürünlerle iç ve dış piyasada rekabet gücümüzü arttırmak gerekmektedir. 
Ülkemizde atık yağ potansiyeli ile ilgili yapıımış çalışmalar istenen düzeyde değildir. Her ne kadar geri dönüşüm tesisleri olsa da birçok restorantta atık bitkisel yağların ve kurumsal olmayan birçok oto sanayide atık motor yağların geri dönüşüm tesislerine verilmediği bilinmektedir (URL2). Çevre ve Şehircilik Bakanlığı ile Tarım Bakanlığı yönetmeliklerinde atık yağlardan elde edilen ürünlerin tekrar insan ve hayvanların kullanabileceği şekle dönüştürülemeyeceği, yem olarak kullanılamayacağına dair kesin hükümler bulunmakla birlikte biyodizel için lisanslı olmayan atık yağ toplayanların bu yasağa uymadığı bilinmektedir (Öztürk 2018). Bazı işletmeler elde ettikleri atık asit yağlarını yem sanayii ile çalışan işletmelere vererek hayvan yemi olarak kullanılmasının önünü açmaktadırlar (URL-3). Bu atıklar hayvan yemi olarak kullanıldığında hayvanlarda toplu zehirlenmelere sebep olabilmektedir (Kaya ve Yavuz 1993). Ayrıca bitkisel ve hayvansal atık yağlar, kanserojen etkiye sahip olduğundan ve insan sağlığına zarar vereceğinden dolayı sabun ve hayvan yemi üretiminde kullanılmamalıdır. Günümüzde bitkisel atık yağlar daha çok alternatif yakıt olarak kullanılmaktadır (Bolat ve ark. 2016, Öztürk 2018). Tek çözüm odaklı olmaktan çıkarmak amacıyla söz konusu atıkların kompozit üretiminde değerlendirilmesi sağlanmalı, böylece atık yağların oluşturduğu çevre sorununa büyük ölçüde katkı sağlayacağı düşünülmektedir. Yağ geri dönüşümü zorunluluktan yapılan bir proses olup katma değeri daha yüksek bir ürüne dönüştürülmesi halinde kullanılabilecek bir üründür.

Bu çalışmada çevresel problemlere neden olacak bazı atıkların kompozitlerde değerlendirilmesi ile ilgili çözümler önerilerek bu kompozitlerin yeni çevresel yaklaşımlara kaynak olacağı düşünülmektedir.

\section{Doğal Liflerin Kullanımı}

Dünyanın ortak sorunu haline gelen çevresel sorunlar ve bunların çözümü için yasal yaptırımlar sürekli artmaktadır. Günümüzde çevreye zararlı atık miktarlarını azaltmaya yönelik çalışmalara ağırlık verilmiştir. Mevcut kaynakların yeniden kullanılabilir duruma getirilmesi maliyet açısından gerekli zorunluluklardan biri olmaya başlamıştır. Atıklardan odun plastik kompozitlerin üretimi son yıllarda dikkat çekmektedir (Adhikory 2008, Ashori ve Nourbakhsh 2009, Animpong ve ark. 2017). Çevresel kirlilik ve küresel ısınma ile birlikte ayrıca sentetik malzemelerin aksine doğal lif kompozitleri kullanımı yaygınlaşmıştır. Cam, epoksi reçineler ve karbon lifleri ile termoplastikler gibi malzemelerin geri dönüşümü çok zordur. Bu nedenden dolayı doğal lifleri içeren kompozit malzemeler, biyobozulabilir özellikte olduklarından dolayı "çevre dostu" malzeme tanımını karşılamaktadır (Eckert 2000, Donmez Cavdar ve Boran, 2016). Kompozit malzemede en fazla tercih edilen doğal lifler pamuk, keten, sisal, kenaf, hindistan cevizi, hint keneviri, şeker kamışı ve muzdur (Santos ve ark. 2008, Spoljaric ve ark. 2009, Donmez Cavdar ve Boran 2016). Doğal liflerin cam gibi alternatiflerine oranla birçok avantaj ve dezavantajı bulunmaktadır. Ekolojik karakterleri, yüksek sağlamlık ve sertlik performansı göstermeleri, biyobozunur olmaları, düşük maliyetleri, aşındırıcı olmayan yapıları, kolay liflendirilebilir olmaları, yüksek dolgu oranları, düşük yoğunlukları, çok geniş ve farklı tipteki lif çeşitliliğine sahip olmaları gibi özellikleri doğal liflerin, neden birçok endüstrisinin ilgisini çektiğini açıklamaktadır. Bununla birlikte üretim sırasında kümelenmeye meyletmesi, düşük termal stabilitesi, nemden etkilenmesi gibi dezavantajları doğal liflerin polimer kompozitlerde kullanımını sınırlamaktadır. Ama bu problemlerin farklı dolgu ve katkı maddeleri kullanılarak en aza indirilmesi mümkündür (Donmez Cavdar ve Boran 2016, Boran ve ark. 2016).

Çevresel kirlenme, sera gazı emisyonları ve fosil kaynaklarının azalmasının sonucu olarak biyopolimerler petrol bazlı polimerlere alternatif olarak düşünülmektedir. Polilaktikasit (PLA), polivinilalkol, selüloz asetat, poli(bütilen süksinat) (PBS), poli(hidroksi bütirat) (PHB), polikaprolakton(PCL), nişasta gibi alifatik polyesterler gibi polimerler biokompozitlerin üretiminde değerlendirilmektedir (Oksman ve ark. 2003, Mohanty ve ark. 2004). Yarı kristalen ya da amorf yapıda olan alifatik polimer PLA'lar, aynı zamanda rijit yapı da göstermektedir. Bu polimer türü polietilenteraftalat(PET) ve polipropilen (PP) özelliğine sahip olup diğer polimer türlerine göre eşsiz bir özellik göstermektedir (David ve ark. 2005). PLA nişastaca zengin bitkisel kaynaklardan üretilmiş olup üstün fiziksel ve mekanik özellikleri, çevre 
dostu, biyouyumluluğu, yenilenebilirliği, biyobozunabilirliği ve nispeten daha iyi bulunabilirliği açısından birçok biyopolimer arasında öne çıkmaktadır. En yaygın kullanılan biyopolimerlerden biridir, ambalaj malzemeler, elyaf üretimi ve son zamanlarda çeşitli uygulama alanlarında geniş bir ilgi görmektedir. PLA çevre dostu polimerler içerisinde kilit bir konuma sahiptir ve gelecekteki gelişmeler için en umut verici polimerlerden biridir. Esnekliği nedeniyle polimer kompozitlerde doğal liflerin takviye olarak kullanılması önerilmektedir (Siakeng ve ark. 2018). PLA ambalaj endüstrisinde, medikal ve paketleme alanında, ziraat ve tek kullanımlık ürünlerde birçok avantajı nedeniyle tercih edilmektedir (Gupta ve ark. 2007). Çizelge 1'de PLA/doğal lif katkılı kompozitlerle ilgili yapılan bazı çalışmalar verilmiştir.

Çizelge 1. PLA/doğal lif katkılı kompozitlerle ilgili son zamanlarda yapılan bazı çalışmalara ait sonuçlar

\begin{tabular}{|c|c|c|c|c|c|c|}
\hline $\begin{array}{l}\text { Doğal lif katkı } \\
\text { türü }\end{array}$ & $\begin{array}{c}\text { Eğilmede } \\
\text { elastikiyet modülü } \\
\text { (GPa) }\end{array}$ & $\begin{array}{l}\text { Eğilme direnci } \\
\qquad(\mathrm{MPa})\end{array}$ & $\begin{array}{c}\text { Çekme } \\
\text { direnci (Mpa) }\end{array}$ & $\begin{array}{c}\text { Elastisite } \\
\text { modülü (GPa) }\end{array}$ & $\begin{array}{c}\text { Darbe } \\
\text { dayanımı }\end{array}$ & Kaynak \\
\hline $\begin{array}{l}\text { Pamuk sapı koçanı//keten lifi } \\
(\% 10,20,30) \text { MAPP }(\% 2)\end{array}$ & $3.30 \sim 4.76$ & $6.39 \sim 49.19$ & & & & $\begin{array}{c}\text { Bajracharya ve } \\
\text { ark. } 2017\end{array}$ \\
\hline $\begin{array}{l}\text { Kızılçam orman budama atıkları } \\
\qquad(\% 40)\end{array}$ & 2770.13 & 47.71 & 24 & & & $\begin{array}{c}\text { Karakuş ve ark } \\
2014\end{array}$ \\
\hline $\begin{array}{c}\text { Parçalanmış atık gazete lifleri } \\
(\% 30)\end{array}$ & 5.4 & 106.2 & 67.9 & 5.3 & $23.5(\mathrm{~J} / \mathrm{m})$ & $\begin{array}{l}\text { Bajpai ve ark. } \\
2012\end{array}$ \\
\hline Hindistan cevizi lifi (0.5) & & 102.9 & 67.99 & 2.37 & $\begin{array}{c}81.37 \\
\left(\mathrm{KJ} / \mathrm{mm}^{2}\right)\end{array}$ & $\begin{array}{l}\text { Bajpai ve } \\
\text { ark.2012 }\end{array}$ \\
\hline Pamuk (\%25) & & & 4.12 & 4.24 & $\begin{array}{c}28.7 \\
\left(\mathrm{KJ} / \mathrm{mm}^{2}\right)\end{array}$ & $\begin{array}{l}\text { Bajpai ve ark. } \\
2012\end{array}$ \\
\hline El yapımı selüloz (\%30) & & & 92 & 5.8 & $\begin{array}{c}11.25 \\
\left(\mathrm{KJ} / \mathrm{m}^{2}\right)\end{array}$ & $\begin{array}{c}\text { Bajpai ve ark. } \\
2012\end{array}$ \\
\hline Abaka (\%30) & 6.51 & 124 & 74 & 5.85 & $5.3\left(\mathrm{KJ} / \mathrm{m}^{2}\right)$ & $\begin{array}{c}\text { Bajpai ve ark. } \\
2012\end{array}$ \\
\hline $\begin{array}{c}\text { Geri kazanılmış selüloz lifleri } \\
(\% 30)\end{array}$ & 6.2 & 82.6 & & & $21(\mathrm{~J} / \mathrm{m})$ & $\begin{array}{l}\text { Bajpai ve ark. } \\
2012\end{array}$ \\
\hline Kendir (\%30) & & & 53 & 8.3 & $\begin{array}{c}11.13 \\
\left(\mathrm{KJ} / \mathrm{m}^{2}\right)\end{array}$ & $\begin{array}{c}\text { Thakur ve ark. } \\
2015\end{array}$ \\
\hline Selüloz nanowhisker (\%5) & & & 37.23 & 1.23 & & $\begin{array}{l}\text { Bajpai ve ark. } \\
2012\end{array}$ \\
\hline Kenevir (\%30) & & & 75 & 7.9 & & $\begin{array}{c}\text { Thakur ve ark. } \\
2015\end{array}$ \\
\hline Jüt (\%50) & & 174 & 152 & 5.3 & & $\begin{array}{c}\text { Thakur ve ark. } \\
2015\end{array}$ \\
\hline Kenaf $(\% 40)$ & & 126 & 82 & 7.6 & $14\left(\mathrm{KJ} / \mathrm{m}^{2}\right)$ & $\begin{array}{c}\text { Thakur ve ark. } \\
2015\end{array}$ \\
\hline Rami (\%30) & & 170 & 52.5 & & $10\left(\mathrm{KJ} / \mathrm{m}^{2}\right)$ & $\begin{array}{c}\text { Thakur ve ark. } \\
2015\end{array}$ \\
\hline Sisal $(\% 30)$ & & & 23.3 & 3.5 & & $\begin{array}{c}\text { Bajpai ve ark. } \\
2012\end{array}$ \\
\hline Odun unu (\%30) & & & 58.28 & 6.22 & $\begin{array}{c}35.96 \\
\left(\mathrm{KJ} / \mathrm{m}^{2}\right)\end{array}$ & $\begin{array}{c}\text { Bajpai ve ark. } \\
2012\end{array}$ \\
\hline
\end{tabular}

\section{Atıkların Kompozitlerde Kullanımı}

Günümüzde çevresel özellikler ve düşük maliyetler nedeniyle kompozit malzeme içerisinde sentetik liflerin yerini alması için doğal liflerin kullanılması cazip hale gelmeye başlamıştır. Selüloz liflerine katılan şeker kamışı, mısır koçanı ve saman gibi selüloz atıkları kompozitlerde dolgu malzemesi olarak yaygın olarak tercih edilmektedir. Odun, talaş, kağıt fabrikası çamuru, tarımsal atıklar ve atık kağıtlar termoplastik kompozitlerde kullanılan doğal lifler 
arasında yer almaktadır. Bunlar içerisinde atık kağıt, katı atık akışının en büyük geri dönüştürülebilir bileşenlerinden biridir. Atık kağıtların en fazla \%50'si değerlendirilebilmekte önemli bir kısmı ne yazık ki değerlendirilmemektedir. Diğer bir ifade ile kağıt üretimi dışında da atık kağıtların büyük bir hammadde kaynağı olarak potansiyeli vardır. Eski gazete kağıtları da oduna benzer özelliklerinden dolayı plastik kompozitler için iyi bir alternatif kaynaktır (Pesman ve Şahinbaş 2017). Geri dönüştürülmüş atık kağıtlar plastik kompozit endüstrileri için dolgu malzemesi olarak ideal bir kaynak olabilir. Literatürde yapılan araştırmalarda polipropilende atık kağıt bardakları \%40 oranında kullanılarak üretilen kompozitlerin mekanik özelliklerinin geliştiği bulunmuştur (Mitchell ve ark. 2014). Ayrıca, atık gazete lifleriyle yapılan bir çalışmada kompozitlerin darbe mukavemetinin arttığı, ancak gerilme ve eğilme mukavemetlerinin azaldığı sonucuna varılmıştır. Bu üretilen kompozitlerin kristalenlik değerinin ve termal stabilitelerinin arttığı gözlenmiştir (Ardekani ve ark. 2014). Düşük yoğunluklu polietilen esterleştirilen ağartılmış odun hamuru ile kullanılarak üretilen kompozitlerin mekanik özelliklerin iyileştiği görülmüştür (Sailaja ve Deepthi 2011).

Genellikle yüksek yoğunluklu polietilen veya propilen gibi plastiklerin ve odun unu gibi dolgu maddelerinin karışımından oluşan odun plastik kompozitlerinde polar olmayan plastikler ve polar yapıdaki odun tozu arasındaki ara yüzey kompozit materyal üzerine bir yük uygulandığında iki evre arasında gerilim transferini sağlayan uyumsuzluk giderici ajan ile gelişme gösterir. Uyumsuzluk giderici ajanlar polimer ve odun tozu gibi katkı maddeleri arasındaki kimyasal etkileşimi sağlamaktadır. Böylece, kompozitin fiziksel ve mekanik özelliklerini olumlu yönde etkileyerek birbirine uyumlu olmayan malzemeler arasında adhezyonu ve dağılabilirliğini geliştirmektedir. Proseslerde kullanılan uyumsuzluk giderici ajanlar maleik poliolefinler (maleik polipropilen veya maleik polietilen), anhidridler veya organik asitlerdir (Klyosov 2007, Animpong ve ark. 2017). Uyumsuzluk giderici ajanlar olarak ayrıca stearik asit, mineral yağ ve maleik etilen lif ağırlığına yaklaşık \%1 oranında kullanılmaktadır. Lifler tarafından mineral yağlar absorbe edilerek lifler arasındaki etkileşime engel olmaktadır. Bu mineral yağlar aynı zamanda polimer içerisinde liflerin ayrılmasını sağladığı bilinmektedir (Saheb ve Jog 1999). Henüz etkin olarak kullanılmayan alternatif olacak bir seçenek de atık bitkisel ve atık motor yağlarıdır. Polimer matrisi içerisinde daha iyi dağııııını sağlamak amacıyla polimer matrisi güçlendireceği düşünülmektedir. Birçok kullanım alanına sahip olacak olan bu atıklardan üretilecek termoplastik kompozitlerin termal, fiziksel ve mekanik özellikleri incelenerek teknolojik uygulamalardaki kullanımına katkı sağlayacağı düşünülmektedir.

Bitkisel yağlar, çeşitli teknolojik uygulamalar için alternatif biyoesaslı bir seçenek olarak ortaya çıkmıştır. Yenilenebilir olmaları, fiyatı ve büyük oranda bulunabilirliği gibi özellikleri sayesinde geleceğin malzemesi olarak adlandırımaktadır (Tan ve Chow 2010, Biermann ve ark. 2011). Atık bitkisel yağlar gıda ürünleri olarak da rekabet etmeyen düşük maliyetli malzemelere olan ihtiyacı karşılama potansiyeline sahiptir. Günümüzde, atık bitkisel yağların kullanımı metil sterlere dönüşümü ve biyodizel olarak kullanımı ile sınırlıdır. Petrol kaynaklarının kullanımıyla karşılaştırıldığında bu atık yağların nihai materyallerin maliyetini düşürmede başarılı bir alternatif olduğu kanıtlanmıştır (Kulkarni ve Dalai 2006, Meng ve ark. 2008). Ayrıca, atık bitkisel yağların teknolojik olarak değerlendirilmesi aynı zamanda ciddi katkılar sağlayan oksijen tüketiminin bir sonucu olarak su yaşamını tehlikeye atan yanlış bertaraf ile ilgili önemli çevresel bir problemi de ele almaktadır (Campo ve ark. 2007, Salam ve ark.2012). Avrupa Birliği'nde yılda 700 000 tondan fazla atık bitkisel yağın ortaya çıktığı tahmin edilmektedir. Sadece Çin'de bu rakam 4.5 milyon ton olup, ele alınması gereken ciddi bir problemin boyutu ortadadır (Gui ve ark. 2008, Felice ve ark. 2017). Türkiye'de atık hizmeti veren belediye sayısı toplamda 1390'dır. Belediyeler tarafından toplanan atık miktarının 2016 yılına kadar toplam 31583553 ton olduğu bilinmektedir. Bu toplam atık miktarına, belediye tarafından ya da belediye adına firmalar aracılığı ile ayrı toplanan geri kazanılabilir atık (cam, kağıt, karton, plastik, metal vb.) miktarları dahildir (URL-4). Ülkemizde kişi başına ortalama bitkisel yağ tüketimi ise 20 kg'dır. Gıdada kullanılmak üzere yıllık yaklaşık 1.5 milyon ton bitkisel yă̆ satışa sunulmaktadır. Rafine tesislerindeki soap-stock, 
tank dibi tortu, yağlı toprak gibi atık yağlarla birlikte yaklaşık 350000 ton atık yağ oluşmaktadır. Bu miktarın ortalama 150000 tonunun fast-food türü gıdaların tüketimindeki artışlara bağlı olarak kızartma için kullanılmış yağ olduğu bilinmektedir. Atık suya karışan kızartma sonucu oluşan bu atık yağlar, evsel atık su kirliliğinin dörtte birini meydana getirmektedir. Bu bitkisel atık yağlar deniz, göl veya nehir suyuna karıştığında çevreye ve insan sağlığına ciddi zararlara neden olmaktadır. Gelişmiş ülkelerde atık kızartmalık yağların gerek kanalizasyona gerek yüzeysel sulara verilmesi yasak olduğundan ötürü bu ülkelerde atık suların kirlilik oranı ülkemizdeki evsel atık sulara kıyasla daha düşük orandadır (URL-1).

Atık bitkisel yağların bir üretim platformu olarak uygulanmasında en büyük zorluk heterojen olmasıdır. Her ne kadar doğal bir malzeme olsa da kızartma işlemi sonucunda termal bir bozunma söz konusudur. Isı, hava ve su kombinasyonu yan ürünlerin karmaşık bir karışımını üreten bir dizi birbirine bağlı transformasyona neden olmaktadır (Paul ve ark. 1997, Choe ve Min 2007). Yağ asidi zincirlerini gliserole bağlayan ester bağları hidroliz, serbest yağ asitleri, mono ve digliseritler oluşturur. Termal oksidasyon reaksiyonları stearik, oleic, linoleik ve linolenik asit türevlerinin oksidatif stabilitesinde farklııklara neden olan hidrojen ve allilik karbon arasındaki nispeten düşük bağ enerjisine bağlı olarak allilik radikallerin oluşumunu tetiklemektedir (Choe ve Min 2007). Benzer şekilde, polimerizasyon mekanizmaları allilik radikaller tarafından başlatılır ve allilik ve alkoksi radikallerin kombinasyonu ile $\mathrm{CeC}$ bağı oluşturarak veya $\mathrm{CeO}$ bağlarıyla alilik radikalleriyle dimerler üretir (Choe ve Min 2005). Bu ürünler yağın fiziksel ve kimyasal özelliklerini derinden etkileyen polimerlerde trimerlerden daha yüksek moleküler ağırlıklı türler oluşturmak için tekrar tekrar reaksiyona girebilir ve birleşebilir (Nawar 1984). Tutkal, plastik ve biyoesaslı epoksi reçineler üretmek için epoksidasyon bitkisel yağların ticari olarak en önemli dönüşümünü temsil etmektedir (Biermann ve ark. 2000, Miao ve ark. 2014). Özellikle epoksi reçineler, trigliseridlerin yapısal özelliği olan uzun alifatik zincirleri direkt olarak malzemenin yapısal özelliklerini etkilemektedir. Bu reçineler diglisidil eter veya bizfenol A (DGEBA)ya dayanan ticari reçinelerle karşılaştırıldığında daha düşük mekanik performans sergileyen termoset polimerleri oluşturmaktadırlar (Niedermann ve ark. 2015). Bu olumsuzlukların üstesinden gelmek için DGEBA ilaveli epoksitlenmiş bitkisel yağların kısmen biyoesaslı karışımları, biyobazlı içerik ve geliştirilmiş mekanik özellikler taşıyan malzemeler araştırılmıştır. Metil nadik anhidrit ve ftalik anhidrit varlığında muamele edilen DGEBA/epoksitlenmiş soya fasulyesi yağı karışımları üretilmiştir. Bu üretilen biyoesaslı malzemelerin darbe dayanımı ve tutkal sağlamlığının arttığı gözlenmiştir (Jin ve Park 2008, Chen ve ark. 2012). Kastor yağı, crambe yağ ve kolza tohumu yağından üretilen farklı epoksitlendirilmiş bitkisel yağlara dayanan benzer sistemler de araştırılmış olup DGEBA esaslı reçinelere nazaran mükemmel termal stabilite ve dayanıma sahip olduğu bulunmuştur (Raghavachar ve ark. 1999, Park ve ark. 2004). Epoksitlenmiş keten tohumu ve soya fasulyesi yağı ilaveli DGEBF karışımlarının darbe dayanımı, kırıma dayanımı ve çekme özelliklerini artırdığı belirlenmiştir (Miyagawa ve ark. 2004, Miyagawa ve ark.). Literatürde bu konuyla ilgili bir dizi çalışma sunulsa da petrol bazı reçinelerde kıyaslandığında bu malzemelerin endüstride uygulanabilirliğinin maliyet açısından rekabet edemeyeceğini öngörmektedir (La Mantia ve ark. 2011). Ayrıca, mühendislikte yenilenebilir yağ kullanımı, toprağın etik kullanımı, gıda zincirinden dışlanma ve dış ticaret ürünlerinin fiyatını nasıl olumsuz etkileyebileceğ konusundaki tartışmaları da beraberinde getirmektedir. Bunun üstesinden gelmek için gıda dışı ürünlerden elde edilen biyo esaslı malzemelerin üretimi araştırılmış ve özellikle çeşitli alanlarda uygulanabilirliği araştırılmıştır (Lligadas ve ark. 2010, Zhang ve ark. 2014).

Diğer bir atık olan motor atık yağların yüzeysel sular ile yer altı suyuna karışması, denizlere drenaj sistemleri ile toprağa verilmesinin çevreye zararlı olduğu bilinmektedir (URL-1). Bir madeni veya sentetik yağ sanayide veya sanayi dışında yağlama özelliği nedeniyle kullanıldığında hem kimyasal hem fiziksel olarak kirlenerek yapısal karakteristiğini kaybetmektedir. Yağ, bileşimindeki katkı maddelerinin kırılması, kir, metal sürtünmeleri, su ve kimyasallarla karışması sonucu koyu bir renk alarak kullanılamaz duruma gelmektedir. Bu atık yağlar ekotoksik özellikte olup bulunduğu ortamda yaşayan canlılara zarar verdiğinden toprağa ve suya atılmaması 
gerekmektedir. Atık yağın içinde yer alan ağır metal ve klor bileşenlerinin hava ile birlikte atmosfere salınarak havayı kirlettiği bilindiğinden yakılması yasaktır. Bir litre yağ beş milyon litre suyu içilemez hale getirirken bir litre kullanılmış motor yağı ise yaklaşık 800 bin litre içme suyunu zararlı hale getirdiği bilinmektedir (URL-2).

Atık yağların toplanması ve ortadan kaldırılması ile ilgili kurallar ilk defa 21 Ocak 2004 tarihinde görüşülmüş olup, "Atık Yağların Kontrolü Yönetmeliği" adında resmi gazetede yayınlanarak belirlenmiştir. Daha sonra mevcut yönetmelik yürürlükten kaldırılmış, ardından "Yeni Atık Yağların Kontrolü Yönetmeliği" 30 Temmuz 2008 tarihinde yayınlanarak yürürlüğe girmiştir. Yeni yönetmelikle, kullanım sonrası ortaya çıkan atık yağlar, içeriğindeki kirleticilerin miktarına göre üç sınıfa ayrımıştır. Birincisi "ürün olarak geri kazanım", ikincisi "enerji değerinden faydalanılarak ek yakıt olarak kullanım", üçüncüsü ise "tehlikeli atık" olarak uzaklaştırılabilir yağlar olarak tanımlanmıştır. Yeni düzenlemeler neticesinde, atık motor yağları sadece motor yağı üreticisi veya yetkilendirilmiş kuruluşlarca alınarak sınıflarına göre muamele edilmesi için lisansı olan işletmelere verilmelidir. Lisansı olmayan kişi ve kurumlar tarafından toplanması ise yasak olup yasadışı yollarla yakıtlara karıştırıması, kontrol olmayan ortamlarda yakılması ve çevreye öylece bırakılması yasaklanmıştır. Atık motor yağları akaryakıta katıldığında çevreyi kirleten emisyonlara sebep olmaktadır. 2013-2018 yılları arasında toplanan 50537 ton atık motor yağının enerji değeri hesaplandığında 553 milyon kwh elektrik enerjisine eşit olduğu bulunmuştur. Bu geri kazanım 300 bin kişinin bir yıllık elektrik enerjisi ihtiyacına eşdeğer bir enerjiye eşittir (URL-5).

Son zamanlarda çevreciler atıkların ormansızlaşma ve ekosistemin tahrip edilmesi üzerindeki olumsuz etkisi üzerine tartışmaya başlamışlardır. Yapılan bir araştırmada atık yağın düşük yoğunluklu polietilenden ve odun unundan elde edilmesi üzerine çalışma yapılmış olup kompozitlerin mekanik ve fiziksel özellikleriyle atık yağın etkileri araştırılmıştır. Normal olarak mineral yağ (esasen hidrokarbon) odun plastik kompozitlerinde formülasyonlarına ekstrüksiyon prosesinde yağlama için ilave edilir. Bununla birlikte, atık otomotiv motor yağının kullanımının etkisi kısmen bu atık yağından türetilen tehlikeli bileşenlerin dışarı atıldığı sentezlenen malzemenin endişesi nedeniyle tam olarak araştırılmamıştır. İyi fiziksel ve mekanik özelliklere sahip atık esaslı odun plastik kompozitlerin gelişimi etkin atık yönetimi yoluyla sürdürülebilir kalkınmayı sağlayacaktır. Yapılan bir çalışmada atık yağ ağırııça \%10 oranında kullanılarak düşük yoğunluklu polietilenle ekstrude edilerek eğilme direnci $13.69^{\prime}$ lük MPa olan bir ürün eldesi mümkün olmuştur. Dış mekânda uygulanabilirliği açısından incelendiğinde ise 24 saat su alma özelliğiyle \%2.85 olan oranla kullanabilir olduğu sonucuna varılmıştır (Animpong ve ark. 2017).

\section{SONUÇ}

Gelişmiş birçok ülkenin en önemli sorunlarından birisi de sanayileşme sonucu ortaya çıkan atıkların nasıl değerlendirileceğidir. Ülkemizde de atık yağların çevreye ve insan sağlığına verdiği zararları minimuma indirmek ve söz konusu bu atıkları yeniden katma değer sağlayacak şekilde geri dönüşüme dahil ederek yeni kullanım alanlarının ortaya konması ve milli ekonomiye katkı sağlamak, çevreci bir ürün üretmek adına çevresel değerlerin ve ekolojik dengenin tahribini önlemeye yönelik çözüm sağlamak, Türkiye'nin katı atık sorununa yardımcı olmak adına araştırmalar yapılmalıdır. Atık motor yağları ve atık bitkisel yağlar ile ilgili birkaç çalışma dışında literatürde atık yağların polimer matrisi içerisinde değerlendirilmesi üzerine ileri düzeyde çalışmalara henüz rastlanmamıştır. Atık kabul tesislerinin tüm dünya genelindeki yüksek maliyetleri olduğundan dolayı, denizlerin de atıkları yok etme, çevreye zararsız hale getirme ve kendini yenileyebilme kaynakları sınırsız olmadığından bu kirliliği azaltma yaklaşımı sergileyecek olan atık yağlardan oluşan kompozit malzeme üretiminde değerlendirilmesi düşünülmelidir.

Tüm bu bilgiler ışığında, birçok kullanım alanına sahip olacak olan yeni, ekonomik, sürdürülebilir ve tamamen atıklardan üretilecek kompozitlerin termal, fiziksel ve mekanik özellikleri incelenerek teknolojik uygulamalardaki kullanımına katkı sağlayacağı düşünülmektedir. 


\section{KAYNAKLAR}

Adhikary KB, Pang S, Staiger MP (2008) Dimensional stability and mechanical behaviour of wood-plastic composites based on recycled and virgin high-density polyethylene (HDPE). Composite Part B-Eng 39: 807-815.

Animpong MAB, Oduru WO, Koranteng J, Ampomah-Benefo K, BoafaMensah G, Akufo-Kumi K, Tottimeh GO, Amoah JY (2017) Coupling effect of waste automotive engine oil in the preparation of wood reinforced LPDE plastic composites for panels. S Afr J Chem Eng 24: 55-61.

Ardekani A, Dehghani A, Al-Maadeed MA, Wahit MU, Hassan A (2014) Mechanical and thermal properties of recycled poly(ethylene terephthalate) reinforced newspaper fiber composites. Fiber Polym 15 (7):1531-1538.

Ashori A, Nourbakhsh A (2009) Characteristics of wooden fiber plastic composites made of recycled materials. J Waste Manag 29: 2911295.

Bajpai PK, Singh I, Madaan J (2012) Joining of natural fiber reinforced composites using microwave energy: experimental and finite element study. Mater Design 35:596-602.

Bajracharya R, Bajwa DS, Bajwa SG (2017) Mechanical properties of polylactic acid composites reinforced with cotton gin wate and flax fibers. In:Rd International Conference on natural fibers: Advanced Materials for a Greener World, Braga, Portugal.

Biermann U, Bornscheuer Meier MaR, Metzger JO, Schäfer HJ (2011) Oils and fats as renewable raw materials in chemistry, Angew. Chem. int. edn. Wiley, Germany, 50, pp 3854-3871.

Biermann U, Friedt W, Lang S, Lühs W, Machmüller G, Metzger JOM, Rüsch gen Klaas, Schäfer HJ, Schneider MP (2000) New syntheses with oils and fats as renewable raw materials for the chemical industry. Angew. Chem. int. edn. Wiley, Germany, 39, pp 22062224.

Bolat D, Can Güven E, Gedik K, Kurt Karakuş PB (2016) Yağ sektörü ürün veya atıklarının alternatif yakıt olarak kullanılmasının çevre ve insan sağlığı üzerine etkileri. U Ü Müh Mim Fak Derg 21(1):25-44.

Boran S, Kızıltaş A, Kızıltaş EE, Gardner DJ (2016) The comparative study of different mixing methods for microcrystalline cellulose/polyethylene composites. Int Polym Proc 31: 92-103.

Campo P, Zhao Y, Suidan MT, Venosa AD, Sorial GA (2007) Biodegradation kinetics and toxicity of vegetable oil triacylglycerols under aerobic conditions. Chemosphere 68:20542062.

Chen Y, Yang L, Wu J, Ma L, Finlow DE, Lin S, Song K (2013) Thermal and mechanical properties of epoxy resin toughened with epoxidized soybean oil. J Therm Anal Calorim 113:939-945.

Choe E, Min DB (2005) Chemistry and reactions of reactive oxygen species in foods. J Food Sci 70:142-159.

Choe E, Min DB (2007) Chemistry of deep-fat frying oils. J Food Sci 72: 77-86.

Clemons C (2002) Wood-plastic composites in the United States: The interfacing of two industries. Forest Prod J 52:10-18.
David E, Henton PG, Lunt J, Randall J (2005) Natural fibers, biopolymers and biocomposites. In: Amar MM, Mohanty K, Drzal LT(ed), CRC Press, pp. 528-569.

Donmez Cavdar A, Boran S. (2016) Doğal liflerin otomotiv sanayinde kullanımı, Kastamonu Univ Orman Fak Derg 16:253-263.

Eckert C (2000) Opportunities for natural fibers in plastic composites. In: Proceedings of the progress in wood fibre plastic composites, Toronto, ON.

Felice C, Fernandes KK, Danielle L, Coles SR (2017) Epoxy resin blends and composites from waste vegetable oil. Eur Polym J 89:449460.

Gui MM, Lee KT, Bhatia S (2018) Feasibility of edible oil vs.non-edible oil vs. waste edible oil as biodiesel feedstock, Energy 33:16461653.

Gupta B, Revagade N, Hilborn J (2007) Poly(lactic acid) fiber: An overview. Prog Polym Sci 32:455-482.

Jin FL, Park SJ (2008) Impact-strength improvement of epoxy resins reinforced with a biodegradable polymer. Mater Sci Eng A 478: 402-405.

Karakuş K, Başboğa iH, Mengeloğlu F (2014) Termoplastik polimer kompozitlerin üretilmesinde orman budama atıklarının değerlendirilmesi, In: II. Ulusal Akdeniz Orman ve Çevre Sempozyumu, Isparta, Türkiye, pp 801-807.

Kaya S, Yavuz H (1993) Yem ve yem maddelerinde bulunan olumsuzluk faktörleri ve hayvanlara yönelik etkileri:1: Organik nitelikli olumsuzluk faktörleri. A Ü Vet Fak Derg 40(4):586-614.

Klyosov AA (2007) Wood-plastic composites, 1st edt. Wiley, New Jersey, pp 1-732.

Kulkarni MG, Dalai AK (2006) Waste cooking oil-an economical source for biodiesel: A review. Ind Eng Chem Res 45:2901-2913.

La Mantia FP, Morreale M (2011) Green composites: A brief review. Compos Part A Appl Sci Manuf 42: 579-588.

Lligadas G, Ronda JC, Galia M, Ca V (2010) Plant oils as platform chemicals for polyurethane synthesis: Current state of the art. Biomacromolecules 2825-2835.

Meng X, Chen G, Wang $Y$ (2008) Biodiesel production from waste cooking oil via alkali catalyst and its engine test. Fuel Process Technol 89: 851-857.

Miao S, Wang P, Su Z, Zhang S (2014) Vegetable-oil-based polymers as future polymeric biomaterials. Acta Biomater 10:1692-1704.

Mitchell J, Vandeperre L, Dvorak R, Kosior E, Tarverdi K, Cheeseman C (2014) Recycling disposable cups into paper plastic composites. Waste Manag 34 (11): 2113-2119.

Miyagawa H, Mohanty AK, Misra M, Drzal LT (2004) Thermo-physical and impact properties of epoxy containing epoxidized linseed oil. Macromol Mater Eng 289: 636-641.

Miyagawa H, Misra M, Drzal LT, Mohanty AK (2005) Fracture toughness and impact strength of anhydride-cured biobased epoxy. Polym Eng Sci 45: 487-495.

Mohanty AK, Wibowo A, Misra M, Drzal LT (2004) Effect of process engineering on the performance of natural fiber reinforced cellulose acetate biocomposites. Composi Part A Appl Sci Manuf 35: 363-370.

Mohanty AK, Misra M, Drzal LT (2005) Natural fibers, biopolymers and biocomposites, Boca Ranton, Taylor \& Francis, pp. 875. 
Nawar WW (1984) Chemical changes in lipids produced by thermal processing. J Chem Educ 61:299-302.

Niedermann P, Szebényi G, Toldy A (2015) Characterization of high glass transition temperature sugar-based epoxy resin composites with jute and carbon fibre reinforcement. Compos Sci Technol 117: 62-68.

Oksman K, Skrifvars M, Selin JF (2003) Natural fibers as reinforcement in polylactic acid (PLA) composites. Compos Sci Technol 63: 13171324.

Öztürk M (2018) Bitkisel ve hayvansal atık yağlardan biyodizel üretimi. Çevre ve Şehircilik Bakanlığı, pp 1-25.

Park SJ, Jin FL, Lee JR (2004) Effect of biodegradable epoxidized castor oil on physicochemical and mechanical properties of epoxy resins. Macromol Chem Phys 205:2048-2054.

Paul S, Mittal GS, Chinnan MS (1997) Regulating the use of degraded oil/fat in deep-fat/oil food frying. Crit Rev Food Sci Nutr 37:635662.

Pesman E, Şahinbaş S (2017) Alkali muamele edilmiş eski gazete kağıdı lifleri ile takviye edilmiş yüksek yoğunluklu polietilen kompozitlerinin fiziksel, mekanik ve termal özellikleri. In:IV. IMCOFE, Rome, pp 293-301.

Raghavachar R, Letasi RJ, Kola PV, Chen Z, Massingill JL (1999) Rubbertoughening epoxy thermosets with epoxidized crambe oil. J Am Oil Chem Soc 76: 511-516.

Saheb N, Jog JP (1999) Natural fiber polymer composites: A review. Adv Polym Tech 18(4): 351-363.

Sailaja RRN, Deepthi MV (2011) Mechanical and thermal properties of compatibilized composites of LDPE and esterified unbleached wood pulp polymer composites. Polym Compos 32 (2):199-209.

Salam DA, Naik N, Suidan MT, Venosa AD (2012) Assessment of aquatic toxicity and oxygen depletion during aerobic biodegradation of vegetable oil: Effect of oil loading and mixing regime. Environ Sci Technol 46:2352-2359.
Santos PA, Giriolli JC, Amarasekera J, Moraes G (2008) Natural fibers plastic composites in automotive applications. In:SPE Automotive Composites Conference \& Exhibition Troy, MI, USA, pp 1-9.

Siakeng R, Jawaid M, Ariffin H, Sapuan SM, Asim M, Saba N (2018) Natural fiber reinforced polylactic acid composites: A review. Polym Compos 1-18.

Spoljaric S, Genovese A, Shanks RA (2009) Polypropylenemicrocrystalline cellulose composites with enhanced compatibility and properties. Compos Part A Appl Sci Manufac 40:791-799.

Tan SG, Chow WS (2010) Biobased epoxidized vegetable oils and its greener epoxy blends: A review. Polymer-PlastTechnol Eng 49:1581-1590.

Thakur VK, Thakur MK, Yu T, Li Y (2015) Handbook of sustainable polymers: Processing and applications. Pan Stanford, Boca Raton, Florida, pp 1-988.

URL-1

http://webdosya.csb.gov.tr/csb/dokumanlar/egitim0008.pdf. Erişim 11.07. 2020

URL-2 (2018) http://cevreonline.com/atik-madeni-yaglar. Erişim 11.07. 2020

URL-3 (2018) http://www.gazetevatan.com/ercan-inan-1208998yazar-yazisi-atik-yaglari-bize-yem-liyorlar-mi-/. Erişim 30.09.2020.

URL-4 (2018) https://biruni.tuik.gov.tr/medas/?kn=119\&locale=tr. Erişim 11.07. 2020

URL-5 (2018) http://www.petder.org.tr/tr-TR/news-detail/son-5yilda-petder-50000-ton-atik-motor-yagi-topladi/627765/2020. Erişim 11.07. 2020

Zhang C, Ding R, Kessler MR (2014) Reduction of epoxidized vegetable oils: A novel method to prepare bio-based polyols for polyurethanes. Macromol Rapid Commun 35:1068-1074. 